\title{
The Morphology of Tensile Failure in Tantalum
}

\author{
BRAD L. BOYCE, BLYTHE G. CLARK, PING LU, JAY D. CARROLL, \\ and CHRISTOPHER R. WEINBERGER
}

\begin{abstract}
The deformation, crack nucleation, coalescence, and rupture process of pure tantalum (99.9 pct) were studied under room temperature quasistatic loading using several in situ and ex-situ techniques including optical metallography, scanning electron microscopy (SEM), electron backscatter diffraction (EBSD), and transmission-electron microscopy (TEM). The fracture surface of tantalum forms a ridge-and-valley morphology that is distinct from conventional notions of ductile dimple microvoid coalescence, and also distinct from spall damage formed during dynamic shock conditions. Failure proceeds by void nucleation at a dislocation cell wall or in subgrain interiors. Coalescence appears to involve a two-stage damage progression: first individual voids coalesce along the tensile axis forming diamond-shaped multivoid cavities; then cavities link-up by intercavity necking. Final rupture occurs when the intercavity necks thin to $\sim 100$-nm films and fail by crystallographic cleavage. This final tearing process was observed using in situ TEM tensile deformation of a thin tantalum film. The detailed microstructural and morphological observations of the current study can be used to guide the development of improved models for tearing of ductile metals.
\end{abstract}

DOI: $10.1007 / \mathrm{s} 11661-013-1814-8$

(C) The Author(s) 2013. This article is published with open access at Springerlink.com

\section{INTRODUCTION}

IN 1959, before the introduction of scanning electron microscopy, Puttick authored "Ductile Failure in Metals," a first detailed look at the process of ductile tearing in copper, iron, and aluminum, using cross-sectional optical metallography. ${ }^{[1]}$ The summary paragraph from this classic text reminds the current reader how far our understanding has come in just over five decades:

To sum up: there are two stages in the formation of a neck in a tensile test. During the first stage the material strain hardens; any holes present are enlarged by the hydrostatic tensions developed in the interior of the specimen and may lead to tensile fracture. When the strain hardening is exhausted localized slip begins on planes of maximum shear stress, and holes may grow into shear fractures on these planes. If fracture does not supervene during either stage, complete slipping-off finally ensues

The proliferation of scanning electron microscopes in the late 1960s permitted first investigations on the morphology of the fracture surface associated with ductile tearing, such as provided by Bauer and Wilsdorf in $1973 .^{[2]}$ These studies revealed the common ductile dimple morphology that is associated with void coalescence. Figure 1 shows classic images of the ductile failure process at different length scales and with

BRAD L. BOYCE, PING LU, JAY D. CARROLL, and CHRISTOPHER R. WEINBERGER, Research Staff, are with Materials Science and Engineering Center, Sandia National Laboratories, P.O. Box 5800, MS0889, Albuquerque, NM 87185-0889. Contact e-mail: blboyce@sandia.gov BLYTHE G. CLARK, Research Staff, is with Physical, Chemical, and Nano Sciences Center, Sandia National Laboratories, P.O. Box 5800, MS 1423, Albuquerque, NM 87185.

Manuscript submitted June 27, 2012.

Article published online June 5, 2013 different imaging techniques. While most of the historic studies associated cavity formation with decohesion at particles or inclusions, ${ }^{[3-5]}$ similar voids were also found in pure metals. ${ }^{[2,6]}$ Two early reviews of ductile failure processes provide additional details on early observations: a 1968 review by Rosenfield ${ }^{[7]}$ and a 1979 review by Goods and Brown ${ }^{[6]}$. Shortly thereafter, Wilsdorf provided a seminal review which focused on microstructural aspects of ductile failure. ${ }^{[8]}$ These observations have led to extensive development of models for void growth and coalescence, with classic contributions by McClintock ${ }^{[9]}$, Rice and Tracy ${ }^{[10]}$, Gurson ${ }^{[11]}$, and Needleman and Tveergard ${ }^{[12]}$. The development of void nucleation models are considerably more limited, with nearly all of the models focusing on nucleation at a second-phase particle interface. Yet, a detailed mechanistic description of the void nucleation process in single-phase ductile metals remains elusive. For a much more detailed description of models for void nucleation and growth, the reader is referred to recent review chapters. ${ }^{[13,14]}$

Still to this day, the mechanical descriptions of void nucleation, growth, and coalescence are based largely on the rather limited experimental observations from the $1950 \mathrm{~s}$ and 1960s. Recent experimental studies have focused on topics like the interaction of an array of premachined holes. ${ }^{[15,16]}$ These new experimental observations have allowed $\mathrm{Xue}^{[17]}$ to formulate a modified constitutive failure model that takes into account both void growth/coalescence and void shearing. Modern characterization tools and experimental techniques could permit a more comprehensive understanding of the ductile failure process in metals. The purpose of the current study is to employ these modern techniques to elucidate the detailed failure process in tantalum, laying 

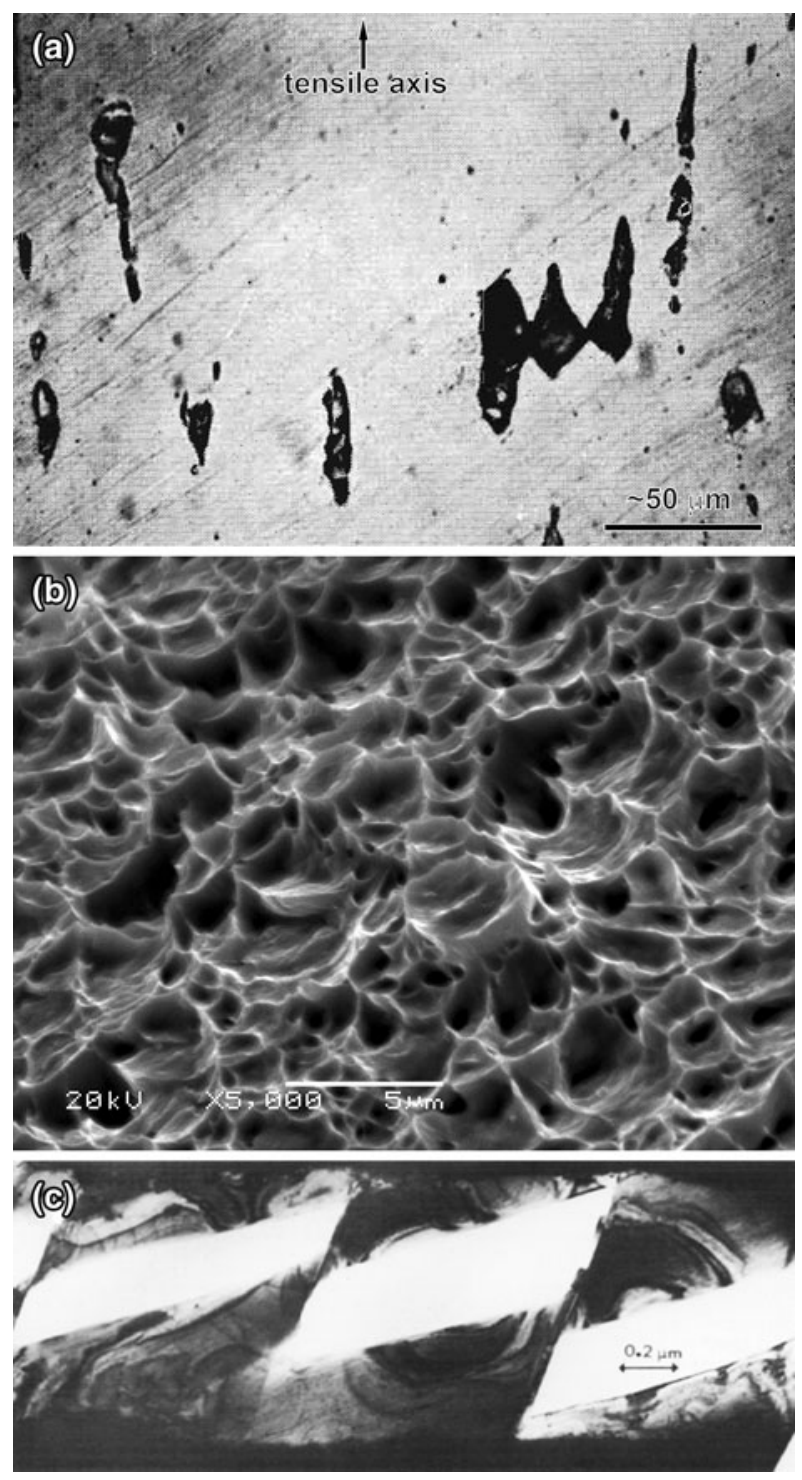

Fig. 1-Classic images of the ductile failure process at different magnifications and with different imaging techniques. (a) optical cross section of cavities formed during deformation of rolled copper 1959 study of Puttick ${ }^{[1]},(b)$ secondary electron SEM image of ductile dimples formed on the fracture surface of $304 \mathrm{~L}$ stainless steel during room temperature quasistatic loading, (c) Sawtooth-type final rupture observed with in situ TEM of high-purity gold at a loading rate ranging from 1 to $10 \mu \mathrm{m} / \mathrm{s}$ from the 1983 study of Wilsdorf ${ }^{[8]}$.

the groundwork for future improvements in failure modeling of tantalum and other metals that fail by a similar process.

Tantalum, a body-centered-cubic (BCC) refractory metal, is often studied for its high-temperature behavior, or its behavior under shock loading conditions. ${ }^{[18-20]}$ The current study seeks to evaluate the failure process of tantalum under low rate loading at room temperature both as a means to understand the material's reliability for applications where these environments are relevant, and as a point of departure to later examine highertemperature behavior. Tantalum possesses good ductility at room temperature and maintains modest ductility even down to cryogenic temperatures. ${ }^{[21,22]}$ In contrast, tungsten, which is also a BCC refractory metal and tantalum's neighbor on the periodic table, is brittle at room temperature failing by a low-energy cleavage process. Under dynamic loading, tantalum fails by a spallation process which progresses by the nucleation of distributed nanoscale voids, followed by void growth and link-up of clusters of voids. ${ }^{[19,20]}$

To further motivate the current study, a preliminary observation of the fracture surface of tantalum was compared with classic ductile, dimpled rupture morphology (Figures 1(b) and 2). This examination of the fracture surface of pure tantalum loaded in quasistatic tension calls into question the validity of traditional void coalescence models for ductile fracture for this material. As shown in Figure 2(a), tantalum deformed quasistatically at room temperature is clearly ductile when loaded in tension, exhibiting a 92 pct reduction in area before separation. However, the fracture surface bears little resemblance to typical ductile dimples associated with void coalescence, such as those shown for 304L stainless steel in Figure 1(b). Ductile dimples are typically hemispherical in nature. ${ }^{[2,6]}$ However, in tantalum, a series of elongated ridgelines and valleys form in the fracture surface. The ridgelines typically range from 10 to $50 \mu \mathrm{m}$ long, much larger than typical ductile dimples. Also, broad, nearly planar facets form between ridges and valleys, reminiscent of brittle cleavage or intergranular decohesion. Finally, a serrated thin film extends along many of the ridgelines, (arrows in Figure 2). From these observations, the question arises as to whether tantalum fracture is associated with a conventional ductile void coalescence mechanism, or some other mechanism.

\section{EXPERIMENTAL PROCEDURE}

Several techniques were used to observe the failure process in tantalum. These techniques included in situ deformation experiments in the scanning electron microscope (SEM) to observe surface slip, crack nucleation, and crack propagation; ex-situ tests where the tensile test was interrupted in the necking regime; and metallographic cross sections that were examined both optically, using the SEM, and using electron backscatter diffraction (EBSD). In addition, the fracture surface was examined post-mortem in the SEM, and focused ion beam cross sections of the fracture surface features were examined using both SEM and the transmission electron microscope (TEM).

\section{A. In Situ SEM Tensile Experiments}

Annealed 99.9 pct tantalum sheet material was procured from Goodfellow Corporation (Oakdale, PA) with dimensions of $300 \times 300 \times 1.5 \mathrm{~mm}$ (Goodfellow product number 000521). The typical chemical analysis for this product is (in ppm): $\mathrm{Al} \mathrm{5,} \mathrm{Ca} \mathrm{2,} \mathrm{Co} \mathrm{1,} \mathrm{Cr} \mathrm{5,} \mathrm{Cu} \mathrm{2,}$ Fe 30, Mg 5, Mn 2, Mo 100, Na 10, Nb < 500, Ni 3, Si 10, Sn 2, Ti 20, V 5, W 100, and Zr 10. No inclusions or second phase particles were found in either SEM or TEM inspection. 

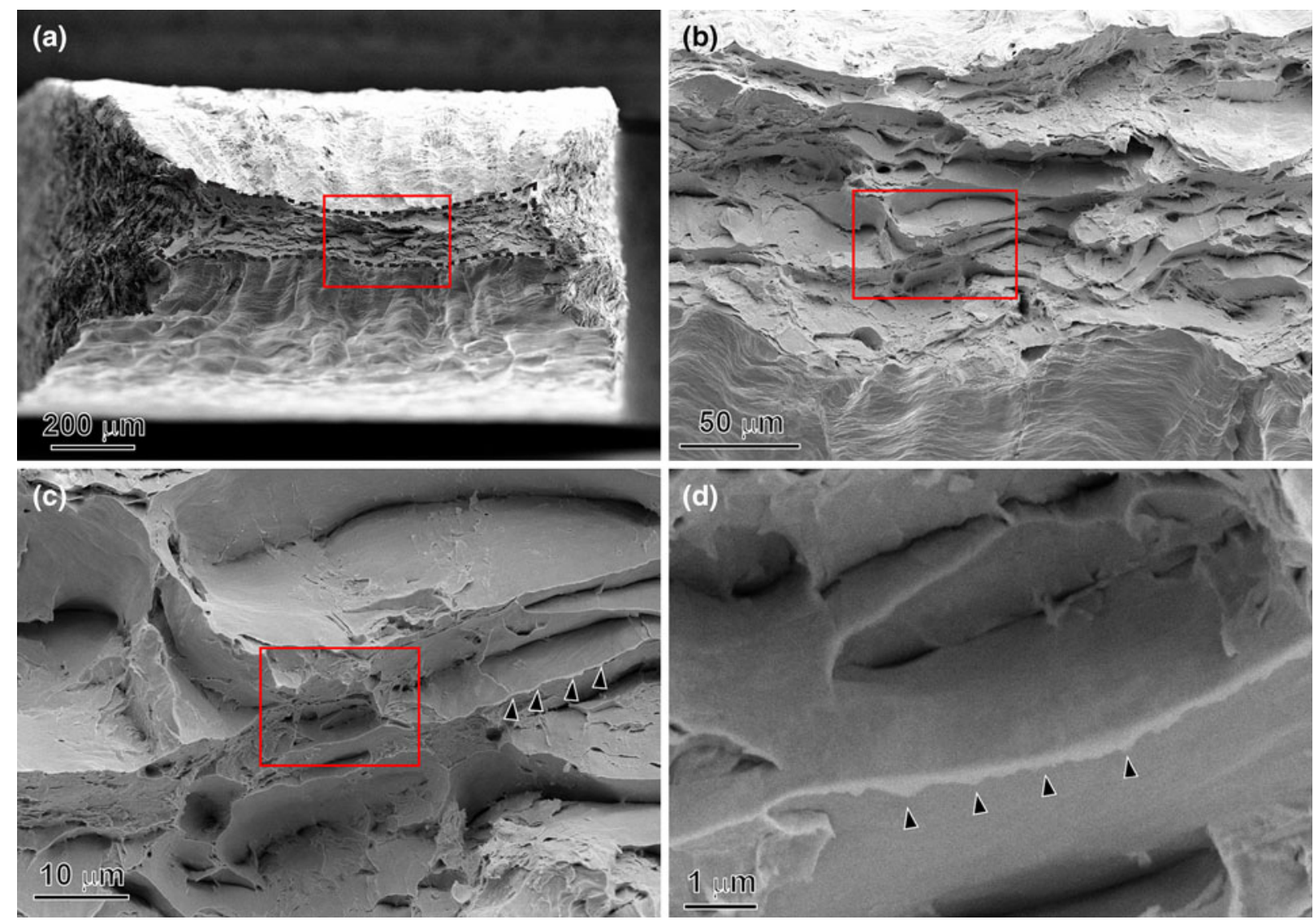

Fig. 2-Scanning Electron Microscope (SEM) images of a fracture surface of tantalum deformed quasistatically at room temperature. Each of the images is a different magnification of the same fracture surface. The tensile axis is out of the plane of the page. Dashed line in $(a)$ indicates the final cross-sectional area at fracture. Arrows in $(d)$ show a thin serrated edge along the fracture ridgelines.

Both smooth bars and notched tensile bars were extracted from the plate using electro discharge machining $(\mathrm{EDM})$. Details of the tensile geometries are shown in Figure 3, and representative stress-strain curves are shown in Figure 4. These miniature tensile bars are similar in shape and aspect ratio to common ASTM E8 standard tensile bars, and even though they are approximately four times smaller than the smallest ASTM E8 tensile bar, their similarity in shape and the presence of a large number of grains within the gage section ( $>20$ grains through thickness) suggest that the observed stress-strain behavior should be similar to bulk conventional tensile behavior. For these small tensile specimens, strain was measured using the digital image correlation (DIC) technique with an Allied Vision Technologies Marlin F146B 1.5 Mpixel digital camera. Speckle contrast was provided by electrostatically adhering a uniform spatial distribution of micron-sized toner particles. DIC image analysis was performed using Correlated Solutions Vic2D software with a virtual extensometer gage length of $4.7 \mathrm{~mm}$.

Based on EBSD measurements, the as-machined tensile bars possessed a preferred crystallographic texture such that [100] and [110] type directions were preferentially aligned along the tensile axis; in other words, there was a dearth of [111] directions aligned along the tensile axis. Before deformation, the grains were equiaxed in shape with an average grain size of $30 \mu \mathrm{m}$ and grain sizes ranging from 10 to $120 \mu \mathrm{m}$.

The planar surfaces of the tensile samples were metallographically polished to produce a $\sim 40$-nm surface finish sufficient for EBSD. First the samples were ground flat using alumina or silicon carbide grinding paper, finishing at a $15 \mu \mathrm{m}$ or 600 grit surface finish. Then, the surface was polished using $9 \mu \mathrm{m}$ diamond on a nylon polishing cloth, with sufficiently low pressure to avoid orange peel effects on the surface. The samples were placed on a vibratory polisher with $0.3 \mu \mathrm{m}$ alumina and de-ionized water for 48 hours, followed by $0.04 \mu \mathrm{m}$ silica for 24 hours.

Displacement-controlled tensile tests were performed in a custom-built in situ electromechanical load frame. ${ }^{[23]}$ The design of the load frame permits tilting the loadframe by up to $70 \mathrm{deg}$, allowing ready access for in situ EBSD experiments. The $2 \mathrm{kN}$ force capacity of the load frame facilitates testing of relatively large tensile bars, such as those shown in Figure 3, and the displacement range of $>8 \mathrm{~mm}$ permits testing to engineering strains of $>100$ pet with active LVDT sensing of actuator displacement. Imaging during deformation was performed on a Zeiss Supra 55VP field emission SEM. Because high-resolution image scans could take several 


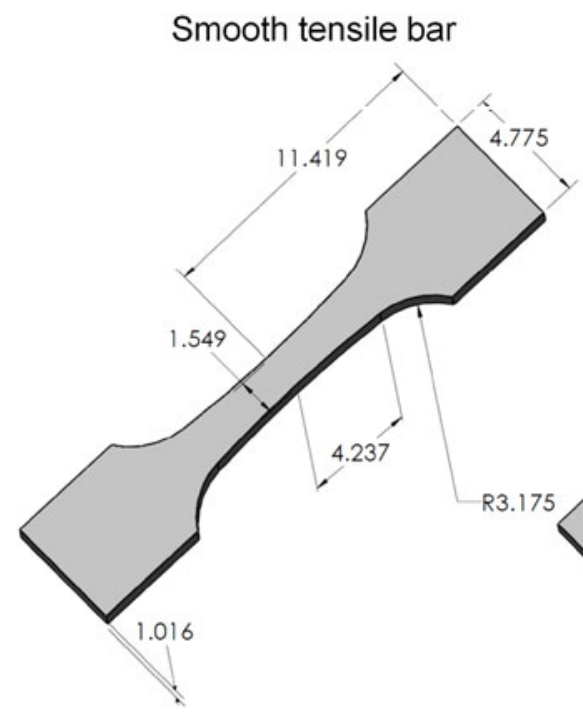

(a)

\section{Notched tensile bar}

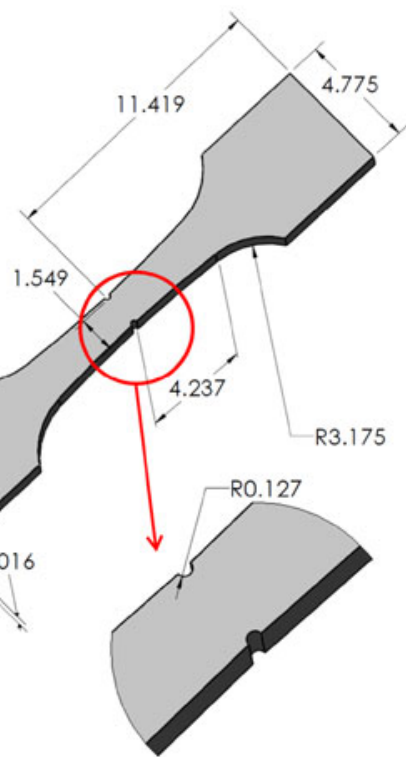

(b)

Fig. 3-Drawing of $(a)$ smooth, and $(b)$ notched tensile bar geometries. Dimensions are in millimeters.
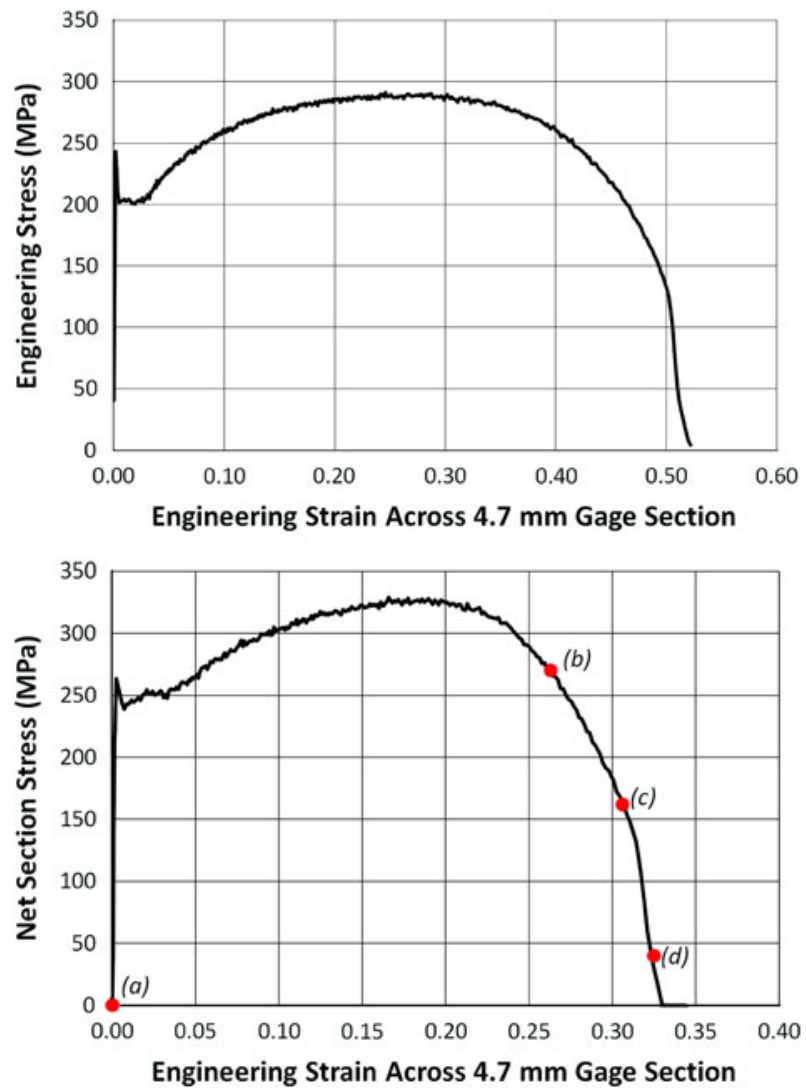

Fig. 4 - (upper) Engineering stress-strain curve for a smooth tantalum tensile bar at room temperature at a strain-rate of $5 \times 10^{-3}$. (lower) Corresponding net stress $v s$ gage strain for the notched tensile bars. Gage strain is the stretch across a $4.7-\mathrm{mm}$ gage length that includes the notched regions. Labels $(a)$ through $(d)$ correspond to the four conditions discussed in Section III-B and represented in Fig. 6. minutes to acquire, the tension tests were not performed at a constant strain-rate, but rather interrupted for imaging. The strain rate between imaging frames was approximately $10^{-2} / \mathrm{s}$.

\section{B. Post-Mortem Cross-Sectional and Fractographic Characterization}

After final failure, the fracture surfaces of mating tensile bar halves were examined in a Zeiss Supra 55VP field emission SEM. In one case, the fracture surfaces were examined in a FEI Helios dual-beam focused ion beam microscope so that a TEM cross-sectional foil could be harvested from the fracture surface using a FIB lift-out and thinning technique. In that case, the $\sim 100$ $\mathrm{nm}$ fracture cross section was subsequently examined in a FEI Tecnai-30F TEM. Other tensile bars were mounted in cross section for optical microscopy of the as-deformed grain structure and corresponding lowmagnification imaging of the cross section of the fracture surface. The cross sectioning was oriented along the centerline of the tensile bar half to expose the $\mathrm{L}-\mathrm{S}$ midplane (the plane that contains the longitudinal and short through-thickness axes). To reveal the grain structure after polishing, those tensile cross sections were etched by swabbing in a solution of equal parts of de-ionized water, sulfuric acid, nitric acid, and 49 pet hydrofluoric acid.

In addition to examining tensile parts after the failure process had led to complete fracture, other tensile tests were interrupted after necking and crack nucleation, but before complete separation. In this case, the tensile bar had been stretched to the point where the cross section in the necked region had contracted to 40 pct of 
the pre-deformation cross-sectional area. Here again, the intact sample was mounted and sectioned to expose the $\mathrm{L}-\mathrm{S}$ midplane. This allowed for the direct observation of the region of highest triaxial stress in the necked region at the center of the tensile bar volume. High-resolution, short working distance, backscattered electron imaging of the polished cross sections in the Zeiss Supra 55VP SEM revealed both the progression of damage, as well as an indication of the deformation-induced subgrain structure. This polished cross section was also studied by EBSD to document the crystallographic arrangement of the grains and subgrains relative to the damage sites.

\section{In Situ TEM Tensile Experiments}

Cold-rolled tantalum sheet with a thickness of $\sim 15 \mu \mathrm{m}$, and a purity of 99.9 pct was purchased from Goodfellow Corporation (Oakdale, PA) for in situ TEM deformation and failure experiments. The sheet was annealed in a vacuum furnace (pressure better than $>10^{-6}$ torr $)$ at $2073 \mathrm{~K}\left(1800{ }^{\circ} \mathrm{C}\right)$ for 2 hours. The annealing produced an equiaxed grain structure with an average grain size of about $25 \mu \mathrm{m}$. A $1 \mathrm{~mm} \times 3 \mathrm{~mm}$ rectangular tensile bar was cut from the sheet, and $\mathrm{Ar}$ ion milling at $5 \mathrm{kV}$ was used to reduce the thickness of the bar in middle to $\sim 3 \mu \mathrm{m}$. After thinning, the bar was further annealed in vacuum at $1873 \mathrm{~K}\left(1600{ }^{\circ} \mathrm{C}\right)$ for 1 hour to alleviate damage caused by the ion milling. The rectangular bar was then attached to a Gatan in situ straining TEM holder for deformation experiments in a FEI CM30 TEM. The 3- $\mu$ m-thick tantalum tensile specimen was initially opaque to electrons at $300 \mathrm{keV}$. However, during deformation (at the rate of $\sim 1 \mu \mathrm{m} / \mathrm{s}$ ), a localized neck formed causing significant reduction in local thickness. Eventually, the tensile bar had deformed to the point where the necked region was electron transparent. This electron transparent neck was the location of subsequent fracture.

\section{RESULTS}

\section{A. Fractography}

Initial observations of the fracture surface of tantalum deformed at room temperature under quasistatic loading are shown in Figure 2. Macroscopically, in Figure 2(a), the fracture surface does not take on a cupand-cone morphology. There are no shear lips present around the periphery of the tensile bar. Instead, the material had necked down to $\sim 92$ pct of its initial crosssectional area, and the remaining fracture surface was roughly orthogonal to the tensile axis. At a finer scale shown in Figures 2(b) through (d), hemispherical dimples are not present. Instead, a series of elongated ridges and valleys populated the fracture surface, ranging typically from 10 to $50 \mu \mathrm{m}$ in length. Invoking analogy to a mountainous terrain is even more apparent in the oblique image of the fracture surface shown in Figure 5. The jagged appearance is more reminiscent of a cleavage or decohesion process rather than a ductile dimple process. The approximately planar facets in Figure 2 bear some resemblance to the grain boundary facets that form when a brittle material has weak grain boundaries that fail preferentially. One may incorrectly surmise from Figure 2 that the planar surfaces are associated with boundary decohesion. In this scenario, one would expect the two mating fracture surfaces to be complementary to one another: a valley in one fracture surface would correspond to a ridgeline in the mating surface. However, examination of mating surfaces suggests otherwise, as shown in Figure 5(b). The two mating fracture surfaces are mirror images of each other: ridgelines found in one fracture surface align with ridgelines on the opposing fracture surface; likewise, valleys found in one fracture surface correlate with valleys on the opposing surface.

\section{B. Damage Progression on the Surface During In Situ SEM Deformation}

Low-magnification SEM images of the planar surface of a double-notched tensile bar are shown in Figure 6. Figure 6(a) shows the tensile bar before deformation, with the tensile axis vertical. Figure 6(b) shows the surface morphology shortly after the forces on the sample had begun to decay, a sign of the onset of necking. The surface had severely roughened due to the deformation. The underlying grain structure apparent in the roughened surface is substantially elongated along the tensile axis. Within individual surface grains, slip traces are often obvious on the surface. In some instances, only a single dominant slip trace is obvious in the grain, whereas in other cases, multiple slip traces are evident. The slip traces are typically quite wavy in nature, and there is often a gradient in slip trace orientation and/or slip trace intensity across the grain, suggestive of the inhomogeneous microstructural-scale strain distribution. ${ }^{[24]}$ Neighboring grains that are plastically incompatible result in pronounced grain boundary seams that extrude from the surface. Some of the most pronounced grain boundary seams undergo localized tearing: not decohesion along the seam plane, but tearing perpendicular to the seam axis. However, these surface seam tears eventually blunt and are not responsible for the final fracture. The notches, which were originally semi-circular, had elongated and roughened extensively. Here again, local tears form in the EDM'd surface of the notch, but those tears blunt and are not responsible for the final fracture.

The fatal crack was first seen on the surface in Figure 6(c). Near the centerline of the surface, a small black perforation, no larger than $5 \mu \mathrm{m}$ across appeared on the surface, shown in the inset of Figure 6(c). The very black contrast of the crack relative to the surrounding surface material seems to suggest that this flaw did not initiate there on the surface, but had initiated subsurface, and as it expanded subsurface, it finally perforated the surface. That surface flaw continued to propagate along a crystallographically influenced path, as shown Figure 6(d), until eventually the tensile bar failed completely. The critical flaw formed at the center of the tensile bar well away from the notches. While maximum strain values were observed to occur at the 


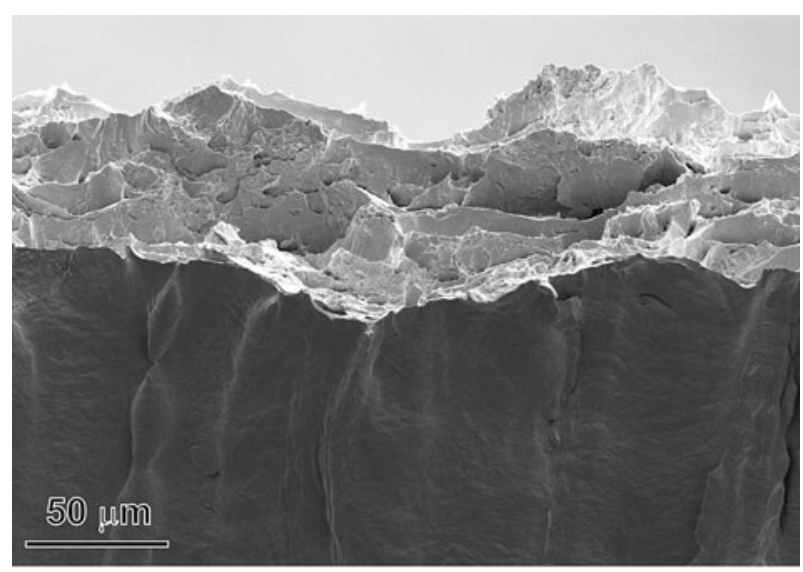

(a)

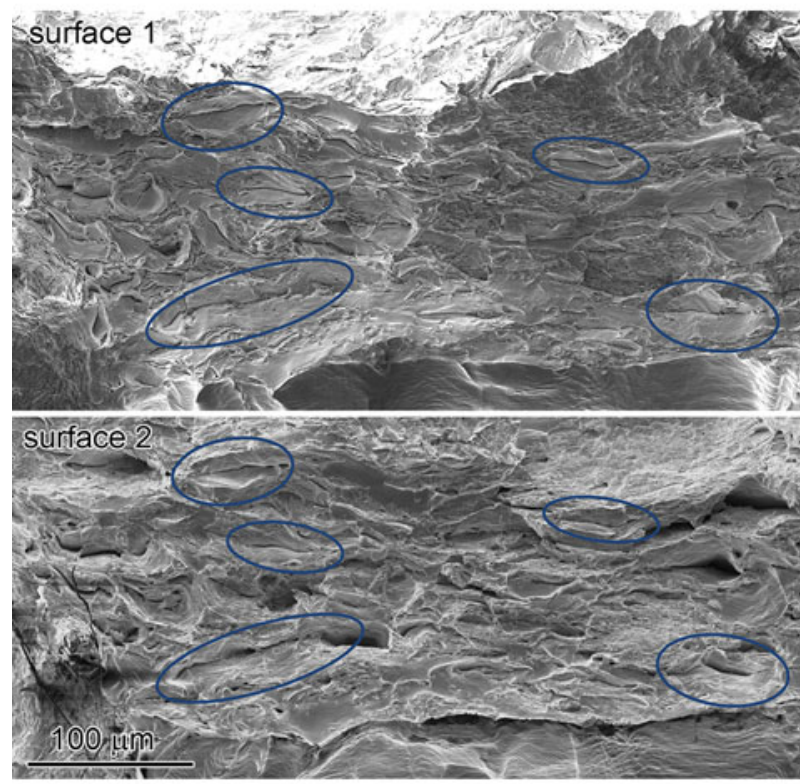

(b)

Fig. 5- (a) Oblique 45 deg-tilted SEM image of the fracture surface. The dark gray region in the bottom half of the image is the deformed surface of the tensile bar, roughly perpendicular to the fracture surface. (b) Images of the fracture surfaces for mating halves of a tensile bar showing mirror-like correspondence between the ridge-and-valley features. "Surface 2" has been inverted to ease comparison with "surface 1".

edge of the notch, the fatal crack did not form at the edge of the notch, but rather at the interior of the sample away from the notch surface, where the triaxial stresses are higher.

\section{Cross Section of Damage State in Late-Stage Necking}

An examination of the mid-plane cross section during late-stage necking of a smooth-bar tensile test just before fracture reveals details of the subsurface damage state. As shown in Figure 7, several damage sites at different stages of development are visible in the necked region of the tensile bar. This late stage of necking contains regions of large cavities that have progressed substantially through the damage process, but also contains fine submicron voids that are presumably newly initiated in regions of microstructure where initiation was somewhat delayed. While the images in Figure 7 are ordered from the lowest-to-highest magnification, the progression in damage likely starts from the nanoscale voids shown in Figure 7(f), and evolves to the much larger cavities visible in Figure 7(b). Several nanoscale voids, less than $100 \mathrm{~nm}$ in diameter are apparent in Figure 7(f), and to the left of the larger void in Figure 7(e). While some of these nanoscale voids appear spherical, others have a distorted shape, presumably due to the imperfect triaxiality of the stress state. The underlying subgrain structure, somewhat visible in the channeling patterns (Figures 7(b) through (f)) suggest that many of the voids formed at subgrain boundaries, although at least one of the nanoscale voids appears to be contained wholly within a single subgrain (arrow in Figure 7(f)). Previous TEM studies have found strings of nanoscale voids formed in close proximity, aligned approximately along the tensile axis, coincident with the elongated axis of the subgrain structure, as visible in Figures 7(d) and (f). These strings of expanding nearly spherical voids begin to link up forming oval-shaped agglomerated cavities, again aligned along the subgrain long axis and close to the tensile axis. When several voids link up, Figure 7(d), they eventually open up into a large $\sim 20-\mu$ m diamondshaped cavity, Figure 7(c). Note that the scalloped shape of the edges of this large cavity is thought to be evidence that individual voids had linked together to form the cavity. To prove conclusively that the large diamond-shaped cavity is the result of a coalescence of cavities along the tensile axis, one would have to observe this subsurface process in situ. To this end, we have attempted in situ X-ray microtomography of the these tantalum tensile bars. However, the thickness of the tensile bars, high X-ray adsorption of tantalum, and limited penetration of commercial laboratory X-ray microtomography machines prohibits sufficient spatial resolution to observe the void link-up process. In the future, a high-flux synchrotron microtomography beamline may be useful to observe this process in situ.

From this same late-stage necked tensile cross section, EBSD was performed on a string of voids that were linking up along the tensile axis. This EBSD result elucidates the crystallographic orientation of the microstructure surrounding the voids, as shown in Figure 8. Figure 8(a) shows the corresponding SEM image of the string of voids that are also visible near the bottom of Figure 7(b). The three orientation maps in Figure 8 correspond to the crystallographic orientation relative to the tensile axis (IPX), transverse in-plane axis (IPY), and surface-normal-axis (IPZ). In Figure 8(b), clearly a vast majority of the grain structure is aligned with [110] parallel to the tensile axis, as seen by the predominance of green in the image. However, there are occasional, thin $(<1 \mu \mathrm{m})$ subgrains of [001] or [111] orientation. These red or purple subgrains are highly elongated along the tensile axis, or at a $\sim 30$ deg inclination to the tensile axis. Each of the voids appear to be associated with one of these thin, inclined subgrains of [001] 

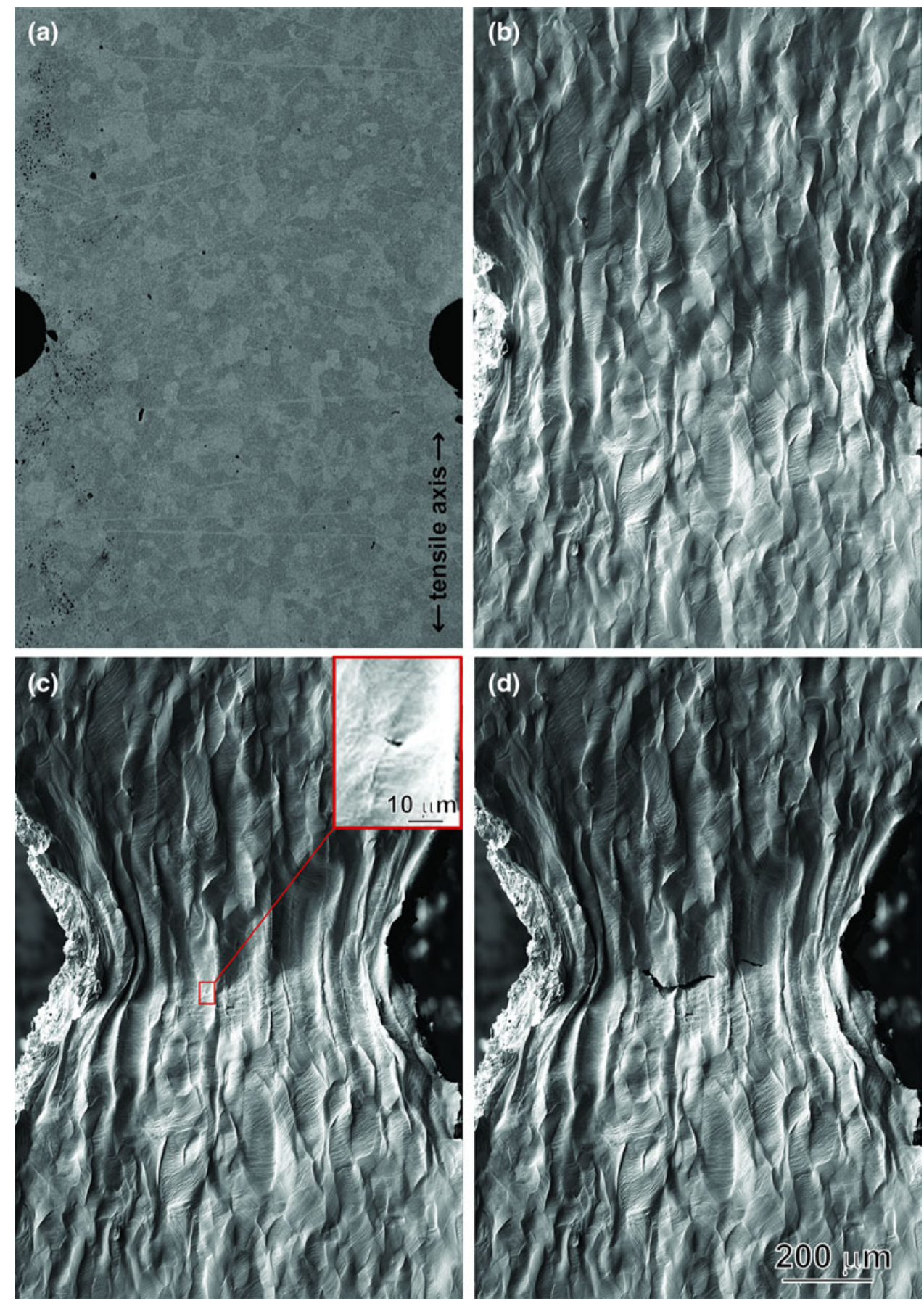

Fig. 6-A sequence of scanning electron images during in situ loading of a notched tantalum tensile bar taken $(a)$ before deformation, $(b)$ just past the point of necking, $(c)$ at the stage where the critical crack has emerged (5 $\mu \mathrm{m}$ long) on the surface of the specimen as shown in the inset, and $(d)$ as the crack is propagating from center toward the sides. Secondary electron imaging was performed at $10 \mathrm{keV}$ and a working distance of $21 \mathrm{~mm}$.

texture, as shown by the arrows in Figure 8(b). From these images alone, it is not possible to quantify the degree of strain in these regions. However, the thin, inclined [001] subgrains alternate with regions of [122] texture, indicating the presence of a high angle boundaries that have formed as a result of extensive deformation. As the arrows indicate, these sharp transitions in orientation associated with intense subgrain dislocation walls, appear to coincide with the void formation.

\section{Cross-Sectional Morphology of Necking and Fracture}

An optical microscope image of the etched centerline cross section of a failed tensile bar half is shown in Figure 9. The distortion of the grain structure is substantial in the necked region. Even away from the necked region, the deformed grains were substantially elongated to an aspect ratio of $\sim 2: 1$ along the tensile axis compared with their original equiaxed shape. In the 

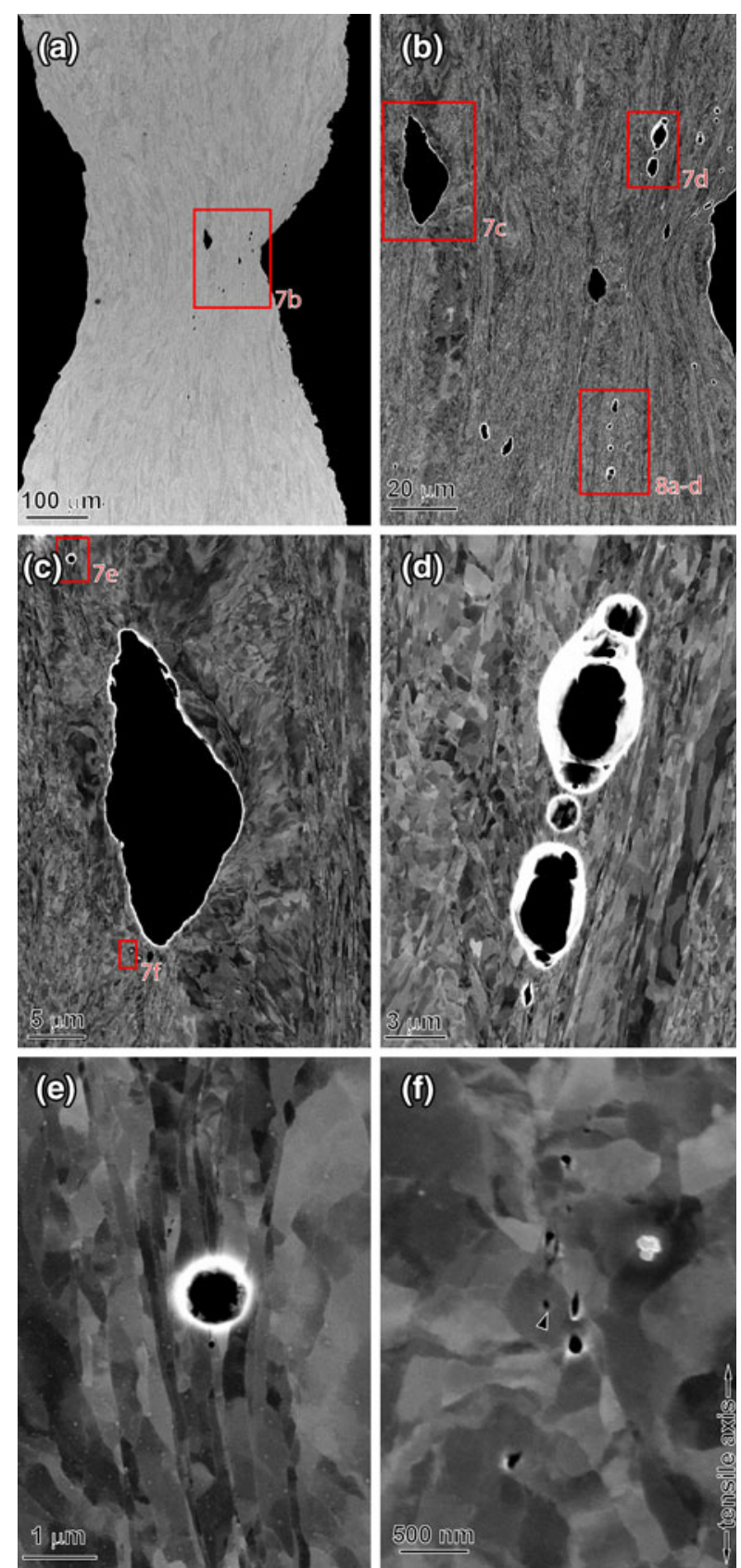

Fig. 7-A cross-sectional SEM image of several voids and cavities at different length scales in a single necked tensile bar. The sample was sectioned along the longitudinal (tensile) axis. Contrast is due to electron channeling, which provides details on the subgrain morphology. To obtain this image, a backscattered electron detector was used with a $15 \mathrm{keV}$ electron beam at a working distance of $4 \mathrm{~mm}$.

necked region, the original grain morphology is difficult to discern due to the extreme deformation. The elongated features in the etched surface of the necked region, which may be original grain boundaries, or subgrain walls, are over $200 \mu \mathrm{m}$ long aligned along the flow lines for the necked region and separated laterally by less than $20 \mu \mathrm{m}$ from one another. Finally, at the fracture surface itself, shown at the top of Figure 9, the macroscopic morphology is evident. The fracture surface has a cup-like shape, but should not be confused
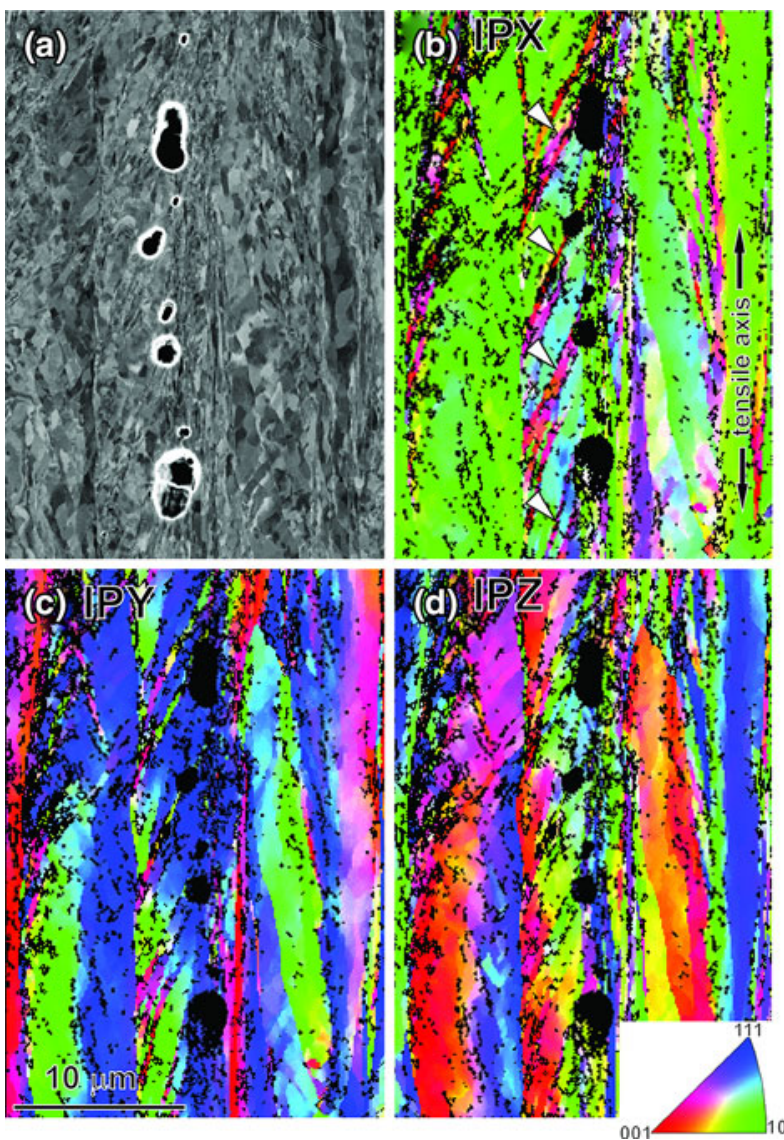

Fig. 8- (a) Electron channeling image of agglomerating voids. The three corresponding EBSD images plot the crystal orientation with respect to the $(b)$ tensile axis, $(c)$ transverse in-plane axis, and $(d)$ out-of-plane axis.

with cup-and-cone fracture morphology where the mating fracture cross section would have a complementary shape. Instead, both fracture surfaces had this concave shape, suggesting that a hole opened in the center of the tensile bar and the edges were the last material to let go. Along the concave fracture surface, a jagged sawtooth morphology is evident, with the saw teeth spaced approximately $\sim 20 \mu \mathrm{m}$ apart, and appearing to correlate with the etched grain boundary or subgrain boundary lines emanating away from the fracture surface. These teeth are the same features that were described as peaks and valleys associated with the fractography of Figure 2.

The optical micrograph does not provide sufficient resolution or detail to determine how the underlying grain structure influences the formation of the peakand-valley fracture morphology. For this reason, a cross-sectional TEM foil was extracted from a single peak-valley-peak sawtooth using the well-established focused ion beam lift-out technique. Figure 10(a) shows an oblique view of the specific peak-valley-peak region that was harvested. The corresponding ion channeling image of the harvested cross section with protective $\mathrm{Pt}$ overlayer is shown in Figure 10(b). Finally, the resulting bright-field scanning TEM (BF-STEM) montage of the grain structure is shown in Figure 10(c). There are many 


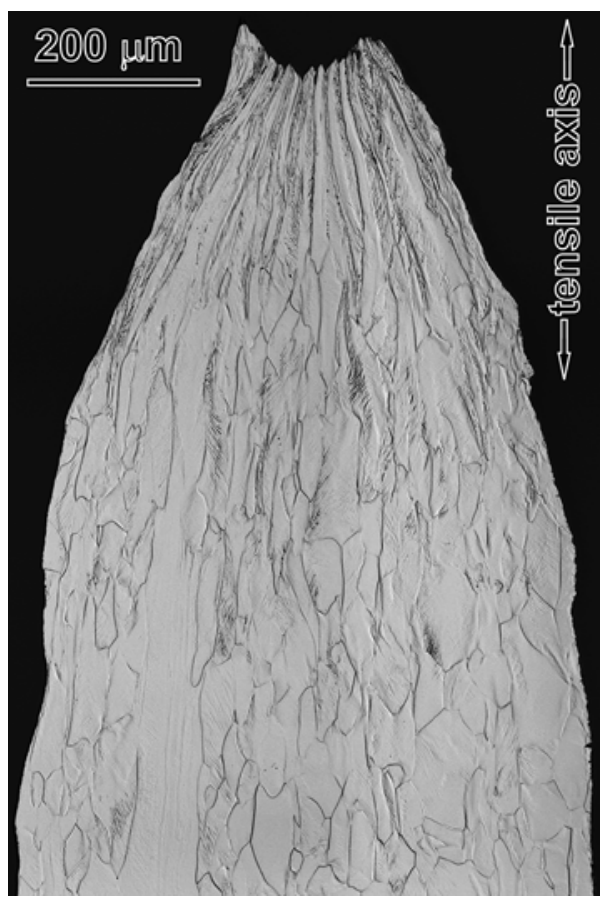

Fig. 9-Optical micrograph of the mid-plane of a failed tensile bar.

subgrains present and an extensive dislocation network within each individual tooth. In this image, there is a vertical white line extending down from the valley between the two teeth, but this white line is merely an artifact. Careful examination of the detailed structure at the valley shown in Figure 10(d) confirms that there is a boundary extending away from the valley, but that boundary does not appear to be notably different from the many subgrain boundaries present within the teeth. Finally, the sidewalls of the teeth are not as planar as they may have appeared in the fractographic image of Figure 2. Rather, a cusp-like morphology is present, and is especially noticeable on the left flank of the right tooth in Figure 10(e).

\section{E. In Situ TEM Observation of Tantalum Fracture}

A 3- $\mu \mathrm{m}$-thick sheet of polycrystalline tantalum was loaded in tension in the TEM until failure occurred. While the sheet was initially opaque to electrons at $300 \mathrm{keV}$, the location of fracture underwent localized necking causing sufficient thinning in the near-fracture region for TEM imaging, as shown in Figure 11(b) through (d). A post-mortem SEM image of the fracture is also shown in Figure 11(a). The thin, sawtooth fracture morphology in Figure 11 was found throughout the fracture zone. This morphology was distinctly different from conventional notions of voids and dimples associated with ductile fracture. Instead, this fracture surface had a sharp serrated appearance, in some ways reminiscent of brittle cleavage. These thin serrated features associated with the final fracture (Figure 11(a)) were also found along the ridgelines of the peaks in the fracture surface of the larger SEM tensile bars, as shown by the arrows in Figure 2. The jagged appearance of the serrations within individual grains of tantalum may suggest a crystallographic "cleavage" plane. The jagged teeth were sloped at angles of $\sim 30 \mathrm{deg}$ with respect to the tensile axis. Diffraction analysis of one particular tooth suggested that the final-failure trace was (310) type in as shown in Figure 11(d). A more detailed study is needed to understand why the fracture forms this particular sawtooth structure.

The dislocation structure in the sawtooth fracture region was analyzed using "g-dot-b" contrast analysis in the TEM. The predominant dislocations were found to be the screw type with the dislocation line along the $\langle 111\rangle$ direction. In Figure 11d, the bright field TEM image was taken in a direction nearly parallel to $\langle 100\rangle$ axis. The dislocations appear as dark lines parallel to the $\langle 110\rangle$ axis in the projection, with the length of the dislocation line proportional to the thickness of TEM specimen. Very short dislocation segments are visible in very thin part of the TEM specimen, close to the tip of the tooth.

\section{DISCUSSION}

The current study on the room-temperature quasistatic failure of tantalum has revealed several observations that may seem surprising or may even contradict conventional notions of fracture in pure refractory BCC metals. Pure tantalum has an impressive degree of ductility, as indicated by $>50$ pct elongation to failure and $>90$ pct reduction in area. It has a moderate degree of work hardening, which leads to a uniform elongation of $>25$ pct, yet tantalum is quite stable after the onset of necking. While by these measures, tantalum is a moderately ductile metal, the jagged faceted fracture surface shown in Figure 2 calls into question whether tantalum fails by the same void coalescence process that causes ductile dimples in other metals.

The cross-sectional images of a highly necked tantalum tensile bar, Figure 7, show evidence of a damage progression that bears similarity to the traditional void nucleation-growth-coalescence process. Based on these images, damage appears to begin as isolated nanoscale voids. However, these voids are not perfectly spherical, but can be distorted perhaps because of the complex stress state that is not perfectly triaxial. Also, the voids appear to cluster together with strings of voids aligned close to the tensile axis, along lines of flow indicated by the long axis of the dislocation subgrain structure. EBSD of one string of nanoscale voids suggests that these voids form in close proximity associated with the periodic arrangement of high-angle subgrain structures. The current observations are reminiscent of the 1977 study by Gardener, Pollock, and Wilsdorf where crack nucleation in beryllium was found to occur at subgrain boundaries. ${ }^{[25]}$ Although, the current observations suggest the possibility that not all voids nucleate at subgrain boundaries (see arrow in Figure 7(f)).

We can only speculate based on the EBSD pattern in Figure 8 that there are specific arrangements of intersecting high-angle cell boundaries that are most susceptible to void nucleation. These specific arrangements 

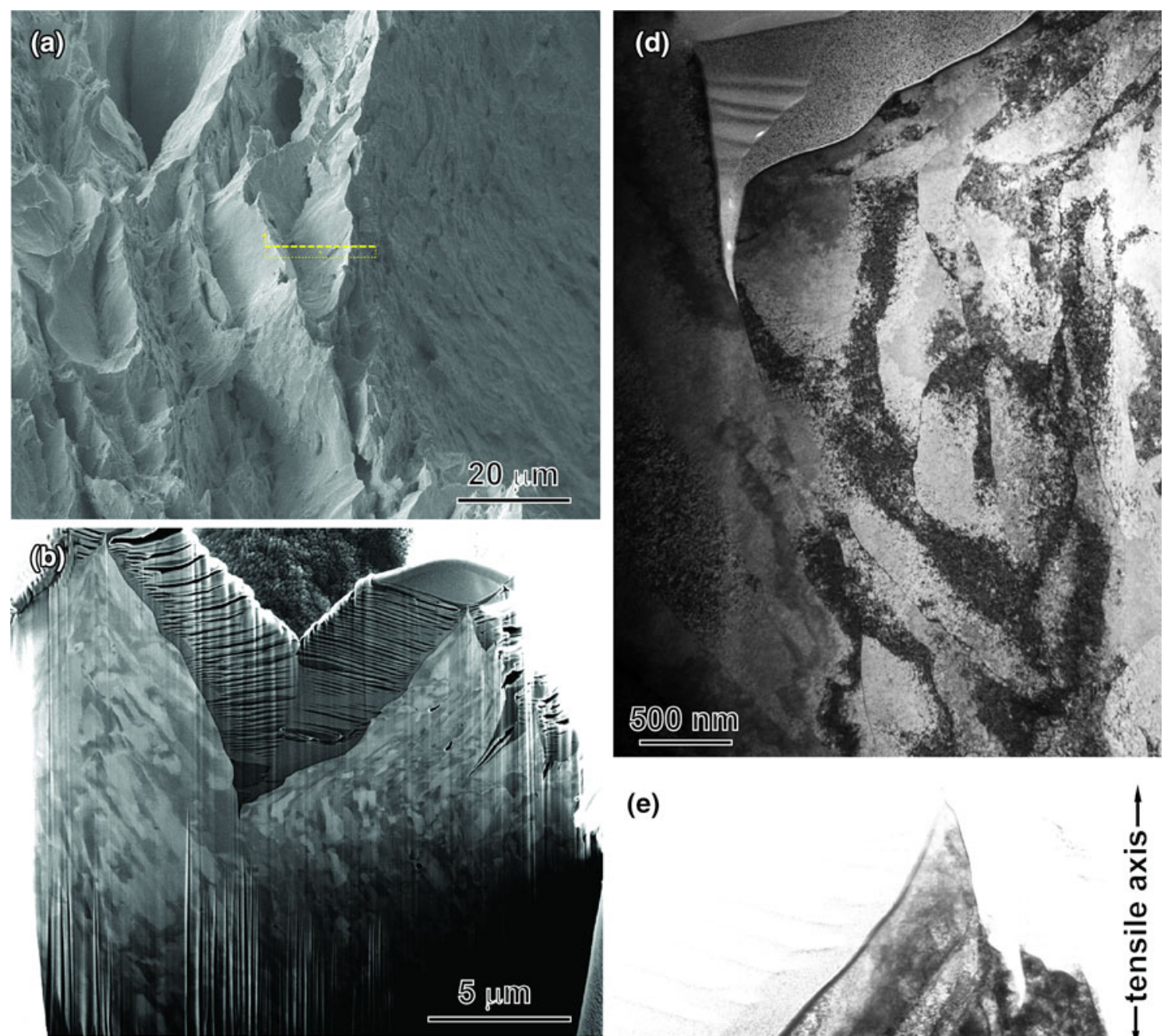

(e)
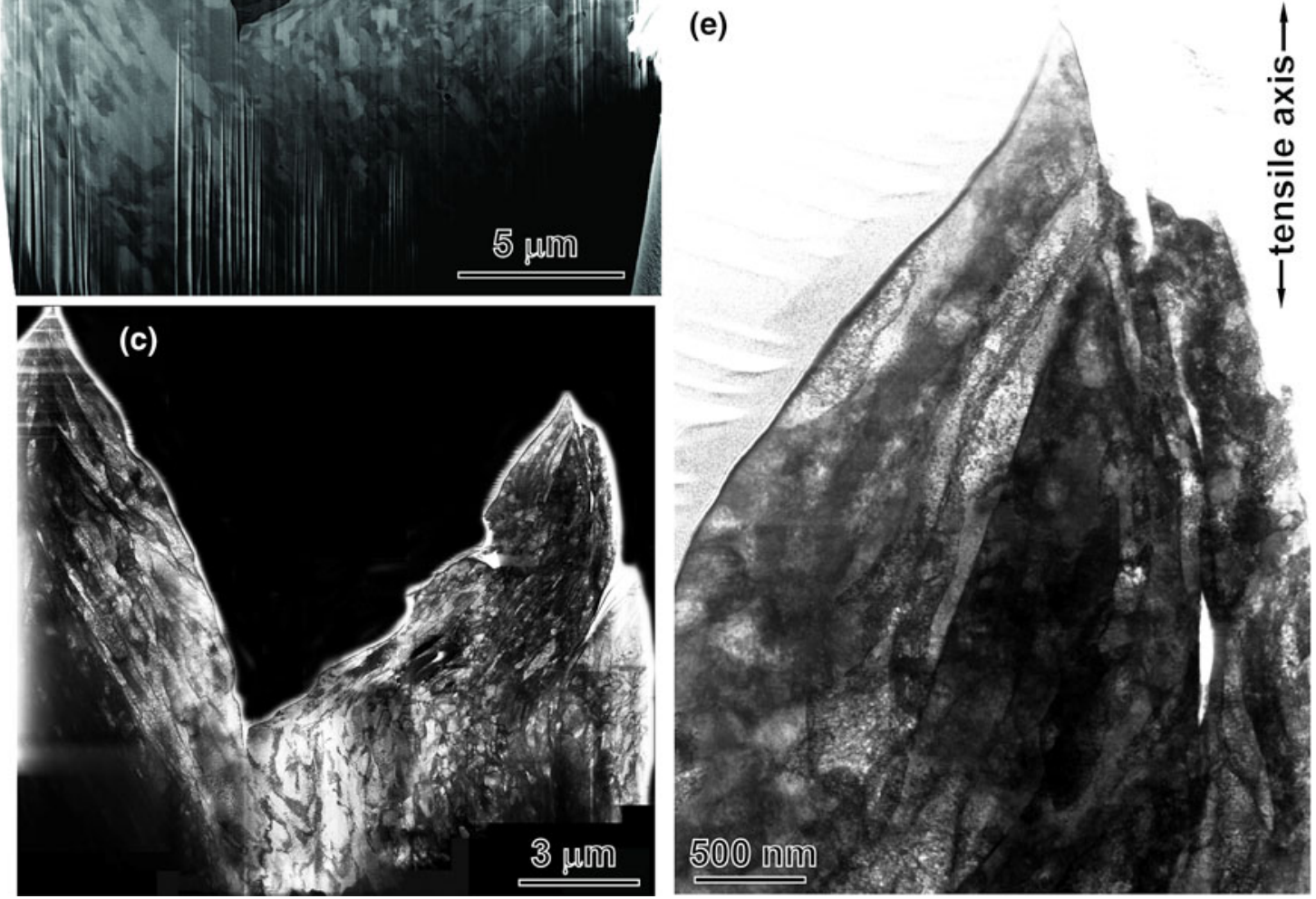

Fig. 10 - (a) Image of the ridgelines and valleys of the fracture surface taken before Focused Ion Beam dissection. Yellow line indicates the location of extracting a TEM foil of two peaks and a valley $(b)$ Ion channeling image of the two peaks and valley covered in a layer of protective Pt, (c) STEM image of the corresponding substructure, with close-up details shown for $(d)$ the valley and $(e)$ the left peak.

presumably form preferred nucleation sites either because the boundaries are highly resistant to slip transmission leading to a buildup of dislocations and elevated stresses, or because the elastic anisotropy of this specific boundary configuration sets up a high degree of triaxiality in the stress state to drive vacancy clustering. This hypothesis is consistent with our recent study using EBSD and DIC strain field mapping to examine the 

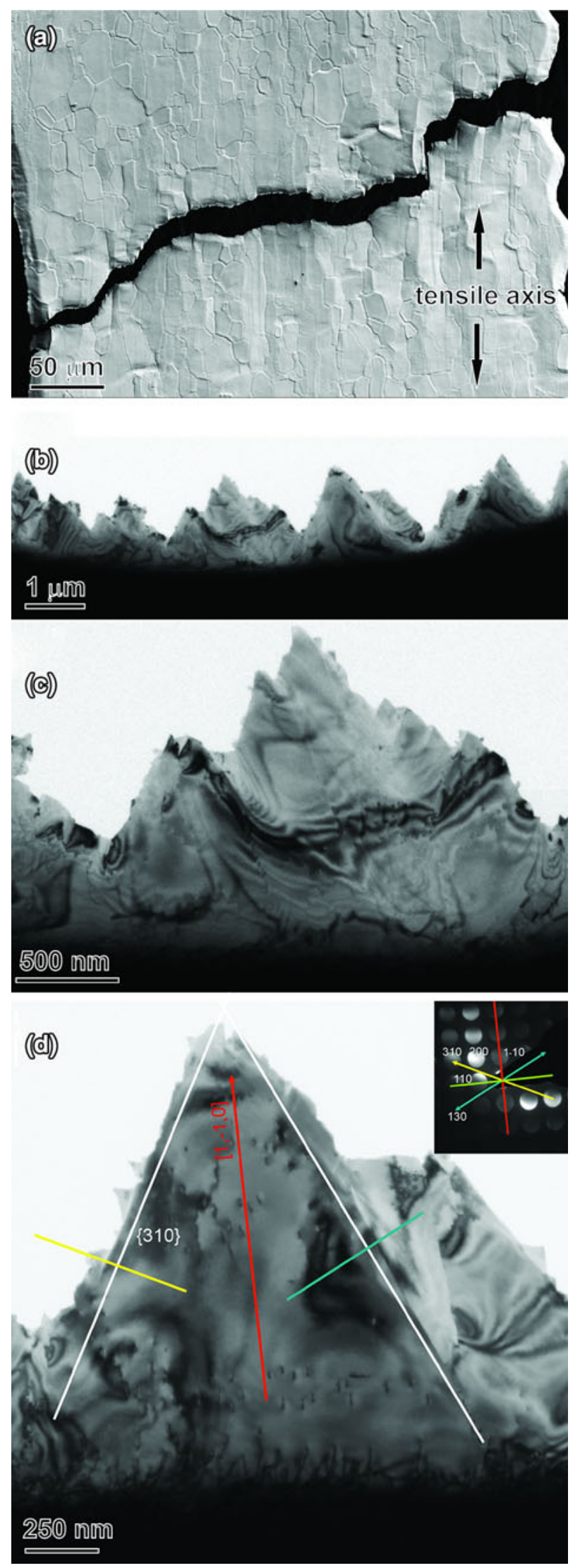

influence of local microstructure on void deformation, where we found that the details of the microstructure can significantly distort the local strain and rotation
4 Fig. 11-(a) Secondary electron SEM image of tensile bar that had fractured during in situ TEM straining, (b) and (c) bright field TEM images of the serrated sawtooth fracture morphology $(d)$ bright field TEM of a single fracture tooth showing dislocation substructure and inset diffraction pattern showing the corresponding crystallographic orientation.

fields in the vicinity of the void. ${ }^{[24]}$ While several existing theories attempt to predict the critical strain necessary for the onset of void nucleation, most of those descriptions do not consider the details of the evolving deformation substructure that establishes preferred nucleation sites.

In Puttick's 1959 article and most subsequent treatments, ductile fracture is described in two stages: spherical void expansion followed by void coalescence. An important observation of the current study is that void coalescence itself can be broken up into substages. Previous concepts of void coalescence have focused on the case where individual spherical voids are arranged laterally with respect to the tensile axis. In this arrangement, the intervoid material along an axis transverse to the tensile axis undergoes localized intervoid necking and failure when two laterally arranged voids merge. However, in the current study, it appears that voids first link up along the flow axis as indicated by the subgrain structure. This first stage of coalescence results in an elongated cavity, generally oriented along the tensile axis, which is built from the link up of more than ten individual spherical voids. This cavity is not spherical in shape. It has scalloped sides from each individual void that caused its formation. During subsequent deformation, the cavity not only continues to elongate causing the scalloped sidewalls to fade, but also stretches along the transverse axis in response to the necking that is taking place macroscopically. The second stage of the coalescence process appears to be the joining of these diamond-shaped cavities within the neck of the tensile bar, this time transverse to the tensile axis. This twostage process, illustrated conceptually in Figure 12, is consistent with the final jagged peak-and-valley fracture surface shown in Figure 2. The peaks in the fracture surface represent the intercavity material that had necked locally to a point just before final fracture. The scalloped sidewalls caused by individual voids within the diamond-shaped cavities are still visible, especially on the righthand side of the TEM cross section in Figure 10(c), and in the diamond-shaped cavity in Figure 7(c).

Is this multistage coalescence process unique to tantalum? Certainly not. The seminal study of Puttick in $1959,{ }^{[1]}$ which formed the basis for subsequent models of void growth and coalescence, revealed similar behavior in rolled copper. As shown in Figure 1(a), diamondshaped cavities are linking up, albeit at a somewhat larger length-scale than observed in the current study on tantalum. It is clear, based on the current results and discussion, that the strings of voids first link up in an elongated fashion along the tensile axis forming cavities. These cavities become diamond shaped and link up transverse to the tensile axis because of intercavity necking. The process is again void coalescence along the 

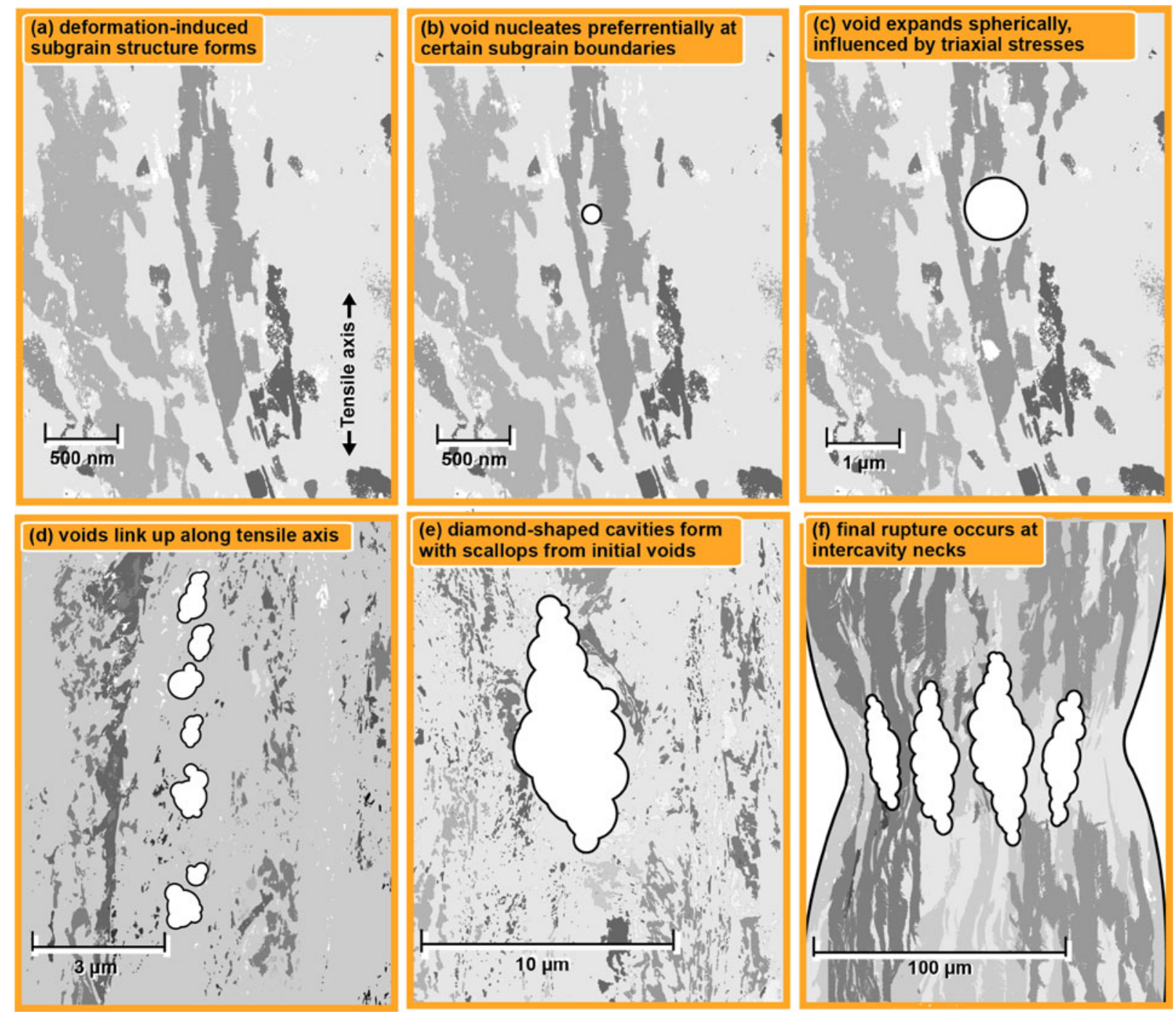

Fig. 12 - Schematic illustrating the key facets of ductile tearing in tantalum. The scalloped sidewalls of the cavity are intentionally exacerbated for illustration purposes.

tensile axis to form cavities, followed by cavity coalescence transverse to the tensile axis. Yet, other metals and alloys such as the stainless steel example provided in Figure 1(b), form a ductile dimple fracture surface which appears quite distinct from the fracture surface discussed in the current study. The models that have emerged for ductile failure appear to bias toward this transverse link-up process which causes ductile dimples in stainless steel, rather than the multistage coalescence process described here for tantalum and copper. This leads to an important question as to why some ductile metals fail in this multistage coalescence process whereas others fail by simple transverse coalescence. One can speculate that there may be important differences in constitutive behavior, deformation-induced subgrain structure, plastic anisotropy, compositional homogeneity, or the presence or absence of secondphase particles that give rise to the different ductile failure morphologies.
The morphology of damage progression in tantalum deformed under slow rate loading presented in the current study is quite distinct from the void morphology associated with tantalum spallation under dynamic loading. The metallographic analysis of tantalum spall damage formed at a loading rate of $246 \mathrm{~m} / \mathrm{s}$ shows very little evidence of microstructural distortion in the vicinity of the voids. ${ }^{[20]}$ With little bulk deformation, void formation occurs at parent grain boundary triple junctions rather than subgrain boundaries. ${ }^{[19]}$ The voids grow spherically to very large sizes, over $100 \mu \mathrm{m}$. Under dynamic loading, the large voids link up transverse to the loading axis, with no evidence of the two-stage coalescence process described in the current study. Further, the link-up of neighboring voids appears to occur with rather sharp cracks between voids with little intervoid deformation, in contrast to the quasistatic behavior observed here where extensive intercavity necking is observed. 
The apparent link-up of voids along the tensile axis could be compared with "necklace coalescence" or "coalescence in columns," as described by Benzerga in Reference 26. Necklace coalescence also leads to substantially elongated voids along the tensile axis. However, it is not clear that the examples of necklace coalescence by Benzerga are directly related to the current observations. First, the elongated voids associated with necklace coalescence are generally much larger in size $>100 \mu \mathrm{m}$ compared with the $\sim 10 \mu \mathrm{m}$ elongated cavities observed in the current study. Second, the process of necklace coalescence has been associated with either laminated composite structures where the laminate delaminates along the tensile axis, or stringers of inclusions aligned along the tensile axis promoting the axial formation of voids. Since the current study was on pure tantalum, there is no such known second-phase feature driving the axial void-formation process. It would be speculative to assert that the elongated dislocation cell structure created a similar predisposition for formation of a string of voids along the tensile axis. Clearly, the limited experimental observations made in the current study should be followed up with more systematic incremental interruption of the damage process to observe the statistics and morphology of damage progression in more detail. In situ X-ray tomography may also provide a means to observe subsurface damage evolution in a nondestructive manner.

The current observations provide new insight into the process of final rupture in tantalum. As cavities begin to coalesce transverse to the tensile axis, intercavity necking occurs. When final failure occurs, those intercavity regions have necked to a sharp point, as shown in the cross-sectional fracture surfaces of Figures 9 and 10. This necking to a point results in the "peaks" or "ridgelines" evident in the fracture surface of Figure 2. However, there is an important detail in this final necked region that forms between cavities. Just before final rupture, the intercavity region necks down to a thin sheet, possibly only 100 to $200 \mathrm{~nm}$, and that final sheet ruptures by an apparently crystallographic process. At the tips of many of the ridgelines in the fracture surface of Figures 2(c) and (d), a thin, serrated sheet extrudes from the ridgeline. This sheet of material, the last to let go, is no longer under triaxial stress, nor can it build up an extensive dislocation network due to the vicinity of the free surfaces. The final failure process is observed in detail during the in situ TEM tensile test represented in Figure 11. The serrated thin film features apparent from the sheet tensile test associated with Figure 11 appear consistent with the extruded serrated material along the ridgelines of a more conventional tensile test in Figure 2. For this reason, the in situ TEM experiment presented here does not characterize the void nucleation, growth, or coalescence process that is associated with fracture in bulk material, but rather focuses on the final low-triaxiality rupture process. It may be difficult or impossible to study high-triaxiality processes such as nucleation and growth during an in situ TEM experiment because of the limited penetration depth of electrons. While molecular dynamics simulations can be set up with triaxial stress, these simulations may lack the necessary length scale and time domain to properly represent the formation of the subgrain structure associated with nucleation, let alone the coalescence process.

These observations of a sawtooth final rupture process observed during in situ TEM are reminiscent of similar features observed by Wilsdorf in high-purity gold, as shown in Figure 1(c). ${ }^{[8]}$ In that study, loading rate was found to influence the formation of the serrated structure: at a loading rate of 1 to $10 \mu \mathrm{m} / \mathrm{s}$, the serrated fracture surface formed, but at a much slower loading rate of 10 to $20 \mathrm{~nm} / \mathrm{s}$, roughly spherical nanoscale voids formed and coalesced ahead of the crack tip. This suggests that the elevated local strain rates in the highly necked region before fracture may lead to this quasi-brittle final rupture. In the early study on gold, the thin film rupture process also formed crystallographic edges to the sawtooth, although in that study, the cleavage traces were along $\langle 112\rangle$ and $\langle 110\rangle$ directions. Wisldorf noted that the TEM evidence suggests that this high-rate deformation occurs by a brittle cleavage process where local stresses are quite high and dislocation activity is suppressed, either because of limited sources or rapid exhaustion. ${ }^{[8]}$

The current study has focused primarily on qualitative observations of the ductile rupture process in tantalum. In addition, study is needed to understand the quantitative microstructural-scale and nano-scale conditions for crack nucleation, growth, and each stage of coalescence. Such quantitative data could be used to calibrate micromechanical models for fracture processes, complementing macroscopic quantities such as strainto-failure and reduction-in-area. At least three such microstructural-scale observations may be within reach in the near future: (1) EBSD of the grain orientation of as-deformed microstructure relative to the initial starting microstructure to quantify local rotations at the onset of failure, (2) local strains associated with failure such as by grain-scale DIC (e.g. $\left.{ }^{[24,27]}\right)$, and (3) local stresses associated with failure such as by inverse methods or the virtual fields method $\left(e . g \cdot{ }^{[28]}\right)$. There are two principal limitations of the aforementioned techniques. First, in ductile metals such as tantalum, the local strains and rotations are extensive, rendering quantification of stress, strain, or absolute rotation difficult. Second, all of the aforementioned techniques can only measure surface quantities, while the critical conditions for void behavior typically begin subsurface. Nonetheless, surface measurements may still be a practical near-term goal for better calibration and validation of phenomenological models, recognizing that such calibration and validation can only take place at the surface.

\section{CONCLUSIONS}

Pure tantalum is a metal with moderate ductility under room-temperature quasistatic loading. The fracture process involves a six-step sequence: (a) subgrain formation during deformation; (b) void nucleation at specific subgrain configurations, which involve high angle boundaries; (c) enlargement of the voids; (d) coalescence of voids along the axis of flow leading to the formation of multivoid cavities; (e) intercavity necking 
transverse to the tensile axis; and (f) final rupture of extensively thinned intercavity necks by a crystallographic cleavage-like process. This six-step process is consistent with, but more detailed than, typical conceptions of a three-step process of nucleation, growth, and coalescence. Evidence from the literature suggests that the observations made here on tantalum may extend to copper and other pure metals. EBSD of micron-scale voids suggests the possibility that there are certain subgrain arrangements, especially those that posses high-angle boundaries, where void nucleation is preferred. Finally, an attempt to study fracture processes using in situ TEM may lack the necessary stress triaxiality condition to observe bulk-like nucleation and growth, but still provides insight into the final serrated rupture process.

\section{ACKNOWLEDGMENTS}

The authors would like to thank Dr. J.R. Michael and B. McKenzie for electron microscopy support, Dr. Henry Padilla for technical review of the manuscript, as well as B.R. Salzbrenner for mechanical testing support. BLB would like to thank Drs. Khalid Hattar as well as Profs. Tom Bieler and Marty Crimp for useful discussions. Sandia is a multiprogram laboratory operated by Sandia Corporation, a Lockheed Martin Company, for the United States Department of Energy's National Nuclear Security Administration under contract DE-AC04-94AL85000.

\section{DISCLAIMER}

This work of authorship was prepared as an account of work sponsored by an agency of the United States Government. Accordingly, the United States Government retains a nonexclusive, royalty-free license to publish or reproduce the published form of this contribution, or allow others to do so for United States Government purposes. Neither Sandia Corporation, the United States Government, nor any agency thereof, nor any of their employees makes any warranty, express or implied, or assumes any legal liability or responsibility for the accuracy, completeness, or usefulness of any information, apparatus, product, or process disclosed, or represents that its use would not infringe privately-owned rights. Reference herein to any specific commercial product, process, or service by trade name, trademark, manufacturer, or otherwise does not necessarily constitute or imply its endorsement, recommendation, or favoring by Sandia Corporation, the United States Government, or any agency thereof. The views and opinions expressed herein do not necessarily state or reflect those of Sandia Corporation, the United States Government or any agency thereof.

\section{OPEN ACCESS}

This article is distributed under the terms of the Creative Commons Attribution License which permits any use, distribution, and reproduction in any medium, provided the original author(s) and the source are credited.

\section{REFERENCES}

1. K.E. Puttick: Phil. Mag., 1959, vol. 4, pp. 964-69.

2. R.W. Bauer and H.G. Wilsdorf: Scripta Metall., 1973, vol. 7, pp. $1213-20$.

3. A. Needleman: J. Appl. Mech., 1987, vol. 54, pp. 525-31.

4. D. Broek: Eng. Fract. Mech., 1973, vol. 5, pp. 55-66.

5. A.S. Argon, J. Im, and R. Safoglu: Metall. Trans. A, 1975, vol. 6A, pp. 825-37.

6. S.H. Goods and L.M. Brown: Acta Metall., 1979, vol. 27, pp. 115.

7. A.R. Rosenfield: Met. Rev., 1968, vol. 13, pp. 29-40.

8. H.G.F. Wilsdorf: Mater. Sci. Eng., 1983, vol. 59, pp. 1-39.

9. F.A. McClintock: J. Appl. Mech., 1968, vol. 35, pp. 363-71.

10. J.R. Rice and D.M. Tracey: J. Mech. Phys. Solids, 1969, vol. 17, pp. 201-17.

11. A.L. Gurson: J. Eng. Mater. Technol., 1977, vol. 99, pp. 2-15.

12. A. Needleman and V. Tvergaard: J. Mech. Phys. Solids, 1984, vol. 32, pp. 461-90.

13. C. Berdin: in Local Approach to Fracture, J. Besson, ed., Les Presses de 1Ecole des Mines de Paris, Paris, 2004, pp. 147-71.

14. A. Pineau and T. Pardoen: in Comprehensive Structural Integrity, I. Milne, R.O. Ritchie and B. Karihaloo, eds., Elsevier, Amsterdam, 2007, pp. 684-797.

15. A. Weck and D.S. Wilkinson: Acta Mater., 2008, vol. 56, pp. $1774-84$.

16. M.A. Zapara, N.D. Tutyshkin, W.H. Mueller, and R. Wille: Continu. Mech. Thermodyn., 2010, vol. 22, pp. 99-120.

17. L. Xue: Eng. Fract. Mech., 2008, vol. 75, pp. 3343-66.

18. Y. Tang, E.M. Bringa, B.A. Remington, and M.A. Meyers: Acta Mater., 2011, vol. 59, pp. 1354-72.

19. A.K. Zurek, W.R. Thissell, J.N. Johnson, D.L. Tonks, and R. Hixson: J. Mater. Process. Technol., 1996, vol. 60, pp. 261-67.

20. J.M. Rivas, A.K. Zurek, W.R. Thissell, D.L. Tonks, and R.S. Hixson: Metall. Mater. Trans. A, 2000, vol. 31A, pp. 845-51.

21. M.A. Adams and A. Iannucci: The Mechanical Properties of Tantalum with Special Reference to the Ductile-Brittle Transition, Part I, Directorate of Materials and Processes, Aeronautical Systems Division, Air Force Systems Command, Wright Patterson Air Force Base, OH, 1961.

22. G.T. Murray and R.A. Burn: The Mechanical Properties of Tantlaium with Special Reference to the Ductile-Brittle Transition, Part II, Directorate of Materials and Processes, Aeronautical Systems Division, Air Force Systems Command, Wright Patterson Air Force Base, OH, 1963.

23. C.C. Battaile, L.N. Brewer, J.M. Emery, and B.L. Boyce: Sandia National Laboratories Report, vol. SAND2009-6169, 2009.

24. J.D. Carroll, L.N. Brewer, C.C. Battaile, B.L. Boyce, and J.M. Emery: Int. J. Plast., 2012, vol. 39, pp. 46-60.

25. R.N. Gardner, T.C. Pollock, and H.G.F. Wilsdorf: Mater. Sci. Eng., 1977, vol. 29, pp. 169-74.

26. A.A. Benzerga and J.-B. Leblond:, in Advances in Applied Mechanics, Vol. 44, H. Aref and E. VanDerGiessen, eds.,, pp. 169305

27. W.Z. Abuzaid, M.D. Sangid, J.D. Carroll, H. Sehitoglu, and J. Lambros: J. Mech. Phys. Solids, 2012, vol. 60, pp. 1201-20.

28. G. Le Louedec, M.A. Sutton, and F. Pierron:, in Advances in Experimental Mechanics Viii, R.L. Burguete, M. Lucas, E.A. Patterson, and S. Quinn, eds., Trans Tech Publications, Durnten, 2011, pp. 135-40. 